\title{
A MATEMÁTICA ESCOLAR, O ALUNO E O PROFESSOR: PARADOXOS APARENTES E POLARIZAÇÕES EM DISCUSSÃO
}

\author{
Viní́cio de Macedo Santos
}

\begin{abstract}
RESUMO: Neste artigo são caracterizadas e discutidas questôes que estão no centro das preocupações e ações do professor de matemática como concepções de conhecimento matemático, de ensino e aprendizagem, a relação entre conteúdo e metodologia de ensino, entre trabalho individual e coletivo etc. Essas questôes têm marcado as atividades de formar professores e de ensinar matemática, assumindo um caráter de dualidades irreconciliáveis ou de paradoxos aparentes com implicaçōes sobre o ensino e a aprendizagem. Considera-se reducionismo indesejável atribuir importância a um dos pólos, desqualificando o outro, ou adotar uma posição multipolar sem que se explicite e compreenda o problema epistemológico subjacente a possíveis antagonismos. Por em questão alguns dos mitos enraizados no nosso ideário de professores pode significar um exercício de reflexão que nos esclareça sobre dificuldades instauradas no ensino de matemática e indique meios para saná-las.
\end{abstract}

Palavras-chave: Ensino de matemática. Ideário do professor. Paradoxos aparentes.

\section{SCHOOL MATHEMATICS, THE STUDENT AND THE TEACHER: APPARENT PARADOXES AND POLARIZATION IN DISCUSSION}

ABSTRACT: This article characterizes and discusses issues which are vital concerns and actions for a mathematics teacher, such as conceptions of mathematical knowledge, teaching and learning, the relation between content and teaching methodology, the relation between individual and group work, and others. These issues have been central in teacher training and mathematics teaching activities,

Pós-doutor em Educação e professor do Programa de Pós-Graduação em Educação da Universidade de São Paulo (USP).E-mail:vms@usp.br 
taking on a character of incompatible duality, or of apparent paradoxes with implications on teaching and learning. It is considered undesirable reductionism to prioritize one of the poles, or to take a multipolar stand without clarifying and understanding the epistemological problem underlying possible antagonism. Questioning some of the myths rooted in our teacher ideology may mean a reflection that will clear our doubts about difficulties established in mathematics teaching and also indicate ways to eliminate them.

Key words: Mathematics teaching. Teacher ideology. Apparent paradoxes.

\section{Polarizações aparentes}

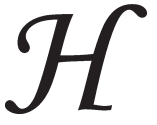

á termos familiares a quem ensina matemática, com forte impacto na sala de aula, que tomam significados curiosos e discutíveis, principalmente quando contrapostos em polarizações muito presentes no nosso ideário e em nossas falas de educadores. Identificam-se alguns desses termos em pares como: individual e coletivo, contexto e conteúdo, instrumento e objeto, método e fundamentos, concreto e abstrato, transmissão e construção do conhecimento, prática e teoria, senso comum e conhecimento científico etc., que, a depender da interpretação, opõem-se rígida e indevidamente a elementos constitutivos do trabalho pedagógico quando podem se articular ou enxergam-se complementaridades forçadas quando podem se opor, dando margem a simplificações que impedem de enxergar com nitidez várias possibilidades daquilo que é importante e necessário ser feito na escola.

Steiner (1993) faz considerações que nos auxiliam no debate sobre as dualidades tratadas neste artigo, quando ele discute a função da Educação Matemática e persegue uma integração entre disciplinas nesse campo. $\mathrm{O}$ autor refere-se às falsas dicotomias tratadas por Hilton (77) (por exemplo, técnica e compreensão, desenvolvimento de estruturas e resolução de problemas, axiomática e construtivismo, matemática pura e aplicada etc.) como pares de posições aparentemente opostas identificadas no percurso da história da matemática e da Educação Matemática.

Na teoria e prática educacional tentou-se muitas vezes esclarecer estes paradoxos de um modo reducionista: ou se atribui domínio absoluto e importância principal a um dos dois pólos, ou se adota uma posição multipolar 
que diz, precisamente, "faça ambos", sem realmente compreender e operacionalizar as relações antagônicas subjacentes que estão de fato relacionadas de forma fundamental com o problema epistemológico da relação entre conhecimento e atividade, visto como o cerne de todas as complementaridades. (Steiner, 1993, p. 29)

Numa prática escolar específica, como é o caso do ensino de matemática, as polarizações têm dupla função: 1) a de vetor que orienta a ação docente, tendo um dos termos do par como a partida e o outro como o objetivo a ser alcançado com essa ação; 2) a de contenda tensionada em que se torna imperativo eleger o pólo positivo do par e com ele identificar-se. Ou seja, qualificar um, desqualificar o outro e tornar-se livre para optar. Nessa contraposição, frequentemente assume conotação negativa o elemento do par a ser ou que já foi superado.

Qualquer uma das duas funções remete a perspectivas teóricas diferentes, a concepções de matemática, de ensino e aprendizagem, a projetos de sociedade ou de homem a que a escola ou o professor procura se filiar.

A seguir serão considerados aspectos de alguns que, no meu entendimento, marcam as práticas na aula de matemática, na formação de professores, na pesquisa e na produção escrita, embora vários desses aparentes paradoxos venham sendo objeto de análise (abstrato e concreto, teoria e prática, transmissão e construção do conhecimento etc.). Insistir na caracterização, por em questão e discutir alguns dos mitos enraizados no nosso ideário de professores de matemática pode significar um exercício de reflexão que nos esclareça sobre dificuldades instauradas em nossas práticas e nos indique meios para saná-las.

\section{Consensos contraditórios}

Dentro ou fora da escola há razoável acordo sobre a necessidade de se ensinar e aprender matemática, dado que se reconhece que noções matemáticas estão na base de boa parte das atividades desenvolvidas na vida. Tal acordo está expresso nos arrazoados da legislação sobre educação e ensino na escola básica, nas justificativas e fundamentação dos currículos oficiais, nas formulações encontradas em estudos realizados e textos produzidos em diferentes tempos, como os de Niss (1995), D’Ambrósio (1996), Machado (1987) e Santos (1990), entre outros. Os argumentos e formulaçóes ressaltam a utilidade da matemática para 
ativar o raciocínio e ajudar a pensar, sua importância em quase tudo o que se faz e, em razão disso, sustenta-se que não saber matemática significa ser, praticamente, analfabeto e que dominar esse conhecimento não é empreitada fácil. Esse consenso sobre a importância e necessidade do ensino e aprendizagem da matemática é exemplo do que pode ou deveria acontecer, na esfera educacional e social, relativamente a muitos pontos inegociáveis de interesse de todo cidadão.

A unanimidade, entretanto, é oposta quando a resposta se refere à experiência de cada um como aluno em matemática. Expressões frequentemente enunciadas na escola ou fora dela revelam certo pessimismo em contraste com o entusiasmo manifestado anteriormente: "a matemática é difícil”, "a matemática é chata”, "eu não consigo entender”, "tenho horror à matemática", "é o bicho papão da escola".

Em resumo, há um consenso quanto à importância e utilidade da matemática na vida dos cidadãos e, contraditoriamente, há quase uma unanimidade em afirmar que mesmo sendo necessário, aprender matemática não é tarefa das mais fáceis e agradáveis.

A organização dos conhecimentos apresentada na escola, bem como o conteúdo trabalhado em cada ano, faz dessa instituição o principal local de difusão de idéias e valores a respeito desses conhecimentos. Por isso, as atitudes e falas do professor contribuem muito com a formação de opiniōes na escola básica, repercutindo e informando os significados dados pelos alunos.

A ambigüidade expressa nesses dois tipos de opiniōes é reveladora dos diferentes significados adquiridos pela matemática e de práticas de ensino. Significados são decorrentes da difusão dada à matemática ao longo do tempo, na escola e além dela, tendo peso preponderante a participação das pessoas no processo formal de ensino. Embora já se tenha criado um folclore a respeito da matemática que acompanha a sua história e transcende a instituição escolar, é o contato com a escolarização, por mínimo que seja, que permite ao cidadão estabelecer relação com noções matemáticas, sabendo que se trata de matemática. Essa experiência, ao contrário do que deveria, pode até ser suficiente para explicitar a importância, mas não para firmar uma aproximação prazerosa e significativa dos aprendizes com a matemática. A relação estabelecida é marcada por sentimentos confusos, rejeiçóes, estigmas. $\mathrm{O}$ destino de muitos dos alunos, no que se refere à sua relação com a matemática, é selado logo nos 
primeiros anos de escolaridade e as razões para isso são várias. Entretanto, para não nos perdermos, cabe neste texto expor e analisar alguns dos pontos que dizem respeito à nossa competência profissional de professores, cuja mudança está ao nosso alcance.

Um exame do que se fala sobre a matemática e seu ensino permite identificar dois campos de significados: um relacionado a aspectos prático-utilitários, que envolve um aprendizado mais "apressado" e que, portanto, ressalta um caráter instrumentall funcional do conhecimento matemático; outro que, sem excluir o primeiro, vincula-se à natureza do pensamento matemático e à necessidade de desenvolver determinados conceitos específicos, ressaltando um caráter mais especializado e até idealizado desse conhecimento. Um conhecimento mais complexo, cujo aprendizado requer mais tempo e dedicação.

Em resumo, a presença da matemática em diferentes contextos e sua forte presença na escola são os principais responsáveis pelo desenvolvimento de uma intuição que conduz as pessoas a atribuírem tanto um significado quanto o outro.

No primeiro caso, trata-se de um significado concreto, pragmático da matemática, determinado pelas exigências de cálculo com operações, medidas, experimentados por todos em situaçóes do cotidiano como: compra, venda, determinação de custos, comprimentos, pesos, porcentagens e solução de problemas corriqueiros. A matemática é um instrumento útil à realização de aspirações imediatas como, por exemplo, dar conta de pequenos desafios do dia-a-dia, ter oportunidades de emprego, melhorar as condições de vida.

No segundo caso, há destaque para uma matemática que todos supõem útil, porém mais avançada e que deve ser confiada ao tempo e à escola. Diz respeito à associação entre a matemática e o desenvolvimento científico e tecnológico - funcionamento de computadores, viagens espaciais, construções da engenharia civil e mecânica, sistemas de satélites etc. - e à economia. Esta matemática, que também tem um caráter instrumental, se vista pelo lado das aplicações práticas, faz parte das aspirações da população, embora como uma meta distante. Sabe-se que o acesso a ela depende do enfrentamento de muitas dificuldades, porque está subordinado ao desenvolvimento da escolaridade, ao aprendizado de noções mais avançadas e do desenvolvimento do que se habituou chamar de raciocínio matemático (Santos, 1990). 
É necessário, porém, analisar esse fenômeno sobre outro ponto de vista. Por um lado, há um conjunto de atividades no dia-a-dia de cada um em que noções matemáticas saltam à vista e favorecem o seu reconhecimento como ferramenta necessária à compreensão do mundo. Por outro lado, há incontáveis atividades em que se pode até desconfiar da presença da matemática sem que seja percebida qual matemática está sendo utilizada e qual sua extensão.

Mogens Niss (1995) se deteve na análise do papel desempenhado pela matemática nas sociedades e a relação estabelecida com ela pelos indivíduos. Refere-se à discrepância entre a transcendência social objetiva da matemática e sua invisibilidade subjetiva, ao que nomeia de paradoxo da relevância, constituído pela simultaneidade da relevância objetiva e da irrelevância subjetiva da matemática. A explicação para as causas de sua relativa invisibilidade na sociedade, segundo esse autor, radica no fato de que a matemática não se encontra na superfície de grande parte das questões às quais estamos atentos, mas está submersa numa espécie de segundo plano e perceptível somente pelos especialistas ou profissionais diretamente envolvidos com as questóes (Niss, 1995). Isso ocorre, por exemplo, com a economia do país, a oscilação das bolsas de valores, cartões magnéticos, códigos de barras, telefonia, a captação e transmissão de imagens e informações pela internet, as previsões meteorológicas em que as informações apresentadas estão baseadas em cálculos e modelos matemáticos pouco visíveis ao usuário comum.

Esse fato, entretanto, não impede que a maior parte das sociedades invista visíveis, ainda que insuficientes, quantidades de recursos na manutenção da investigação, da educação e de outras atividades em que a matemática tem lugar. Possivelmente, essa é uma decisão calcada na convicção de que a matemática é elemento integrante quer do desenvolvimento científico e tecnológico, quer do bem estar da sociedade (idem, ibid.).

\section{O valor positivo da matemática e as dificuldades no seu aprendizado}

No que é dito da matemática encontram-se idéias que reforçam aquelas duas características, a de conhecimento instrumentallfuncional e a de conhecimento especializadolidealizado. Significados são atribuídos 
e podemos perceber que eles revelam concepções que já estão enraizadas nos discursos das pessoas e até guiando práticas escolares, alimentando um circulo vicioso e contribuindo com o deslocamento da matemática para o centro das preocupações escolares e também com o aumento das dificuldades verificadas no momento da aprendizagem.

Os significados presentes no ideário coletivo têm o mérito de evidenciar a importância da matemática. Todos são capazes de lhe atribuir um valor positivo que transcende as afinidades pessoais e as dificuldades que muitos vêm enfrentando, ou enfrentaram na escola. Ao mesmo tempo em que a matemática é um conhecimento cuja compreensão é marcada por dificuldades e do qual nem todos conseguem se aproximar, ela também é reconhecida como uma necessidade. Entretanto, são significados que, no limite, opõem matemática pura e aplicada (Santaló et al., 1994), conhecimento referencial e conhecimento formal, conteúdos e contextos, teoria e prática.

Essa positividade conferida à matemática é pontuada por uma atitude de identificação e proximidade, uma vez que recorremos a ela em situaçóes práticas para as quais precisamos aprender pelo menos a contar e a fazer as quatro operações fundamentais. Também transparece certa reverência frente a características menos familiares da matemática (linguagem, cálculos, aplicações em situações complexas) com freqüência associadas ao desenvolvimento tecnológico e ao conhecimento científico. Aquilo que se diz da matemática, portanto, destaca seu valor como conhecimento que nos ajuda a compreender e explicar certos aspectos da realidade (Santos, 2002).

A correspondência entre positividade e interesse pela matemática não é direta, além do interesse imediato, tendo em vista a necessidade que todos nós temos de lidar com noções matemáticas elementares (contagem, operaçôes, medidas) no nosso dia-a-dia. Esse interesse também está presente na escola devido à enorme expectativa que cerca a aprendizagem da matemática e devido às obrigações aí geradas (sem saber matemático não se aprende outros conhecimentos, é importante acertar as contas, resolver problemas, o esforço de cada aluno em geral é recompensado com notas e elogios, a desatenção ou algum tipo de erro provocam reclamaçóes dos professores etc.).

As pressões presentes na escola também dão ao ensino de matemática um caráter disciplinador, responsável pela criação de interesses 
e expectativas, reforçando e cristalizando imagens logo no início da formação matemática dos alunos: a matemática é difícil, é abstrata, é exata, não é para mim, é chata etc. Não raramente, há entre os professores aqueles que sinceramente acreditam nisso e também colaboram com a difusão desse ponto de vista. Pouco a pouco, expressões como essas ganham força e, tal como boato, passam adiante sedimentando uma rede de impressões, juízos e desconfianças relativos à matemática que se antecipa a qualquer esforço mais sistemático de aprendizagem e alimenta um círculo vicioso.

\section{Individual e coletivo}

No par individual x coletivo, identificam-se duas perspectivas teóricas distintas que, há muito, vêm dando fundamento à expressiva parte dos estudos que abordam o conhecimento dos alunos e dos professores sobre noções matemáticas e que têm influenciado o desenho de projetos curriculares no Brasil e em outros países. Tratam-se da perspectiva piagetiana da cognição humana enquanto construção individual e da perspectiva vigotskiana da cognição enquanto construção sócio-cultural. Dessas duas perspectivas derivaram, respectivamente, a visão da aprendizagem, em matemática, como um processo individual subordinado ao desenvolvimento de estruturas cognitivas de cada sujeito e apenas marginalmente influenciado pelo contexto sócio-cultural; e a visão de aprendizagem como um processo inerentemente sócio-cultural, conforme Abreu (1995). A discussão do alcance e limites de cada uma dessas perspectivas evidencia o fato de que a pergunta formulada por cada um dos pesquisadores tinha partidas diferentes, confirmando o ponto de vista de Charlot (2006), segundo o qual os avanços verificados no campo das ciências do homem e da sociedade decorrem dos pontos de partida e esses pontos podem ser tantos quantas são as perguntas formuladas. No primeiro caso, a pergunta foi: Como um sujeito conhece e passa de um estado de conhecimento a outro? No segundo caso: Que papel desempenha o entorno sócio-cultural na construção do conhecimento? (Castorina, 1995). As considerações de Abreu (1995) indicam possíveis limites que se podem identificar nessas duas perspectivas e afirmam a possibilidade de outras vertentes que, de modo mais integrado, procurarão dar respostas a questões agora formuladas ou àquelas insatisfatoriamente respondidas, como é o caso da perspectiva das 
representações sociais que, a meu ver, articula o modo particular de um sujeito singular manifestar idéias, significados e valores construídos, escolhidos e legitimados em práticas sociais.

$\mathrm{O}$ individual e o coletivo representam duas dimensōes importantes que não se contrapóem nem se rivalizam quando o objeto de análise são os sujeitos e os processos relacionados com o ensino de matemática. $\mathrm{O}$ individual e o coletivo são dois momentos, dois contextos, dois processos imprescindíveis e inerentes à prática na sala de aula de matemática. Significa considerar que o sujeito individual e o domínio do social são indissoluvelmente interconectados (Ernst, 1994). Supõese, portanto, que os sujeitos e, por extensão, o seu conhecimento são formados mediante interaçóes com outros sujeitos, assim como pelos seus processos individuais, pelo modo particular e pessoal com que cada um reflete, atribui significado e age. Assim, cada aluno aprende e se relaciona com a matemática mediante um processo singular, individual, mas marcado por elementos provenientes da coletividade externa ou interna à sala de aula. A sala de aula é um ambiente propício a um trabalho cooperativo, tendo em vista que os diferentes tipos de relações nela estabelecidas apresentam um potencial a ser explorado em favor do ensino e aprendizagem. Por um longo período nela ocorre um conjunto de relações entre alunos e entre estes e o professor, manifestam-se diferentes interesses e diferentes pontos de vista, os sujeitos, ao participarem das atividades, trazem diferentes contribuiçôes e, mediante a comunicação, podem partilhar compreensões e significados na resolução de problemas, no debate de um tema, na realização de um projeto. Tais possibilidades aproximam a sala de aula da idéia de comunidades de práticas, ${ }^{1}$ como postulado por Lave e Wenger (1991).

Se a cooperação é uma possibilidade, o inverso impõe-se de maneira forte no ambiente educacional em que as relaçôes interpessoais sejam frágeis ou não estejam orientadas pela perspectiva de um projeto coletivo. Como estudantes ou como professores somos testemunhas de práticas na escola que tendem a inibir nossa participação, a calar nossas questôes e dúvidas, que não nos encorajam a discutir, por exemplo, situações e idéias matemáticas, nossas estratégias e soluções para problemas propostos, promovendo a condição de indivíduos isolados num espaço. Se essas práticas têm sido próprias da escola, na aula de matemática, em particular, e no ensino de matemática, de maneira geral, têm encontrado terreno fértil para se reproduzirem e se perpetuarem 
(Santos, 2002). A despeito das interações e vivências coletivas que a escola pode proporcionar, no ensino de matemática têm muita força e impacto sobre os sujeitos envolvidos a sistemática de avaliação, ações centradas no esforço e mérito individuais (provas, desafios, olimpíadas), as abordagens que hipertrofiam procedimentos algorítmicos e rituais de memorização, que interpretam a idéia, stricto sensu, de que a aprendizagem é um processo que se dá no indivíduo. Também somos testemunhas, concordando com Ortega (2000), de que o processo de modernização da sociedade, a inserção de jovens e mulheres no mercado de trabalho, a própria mobilidade das opçóes de trabalho e consumo, o ingresso na escola ou a saída dela etc. tendem a promover uma individualização dos sujeitos, adulto ou criança, forçando-os a se desprenderem de vínculos familiares e profissionais de um determinado tipo e a estabelecerem outros conforme a situação e o contexto em que transitam.

Vale para estudantes e professores aquilo que Ortega indica como contraponto e resistência às condições que promovem essa individualização: cada sujeito pode ser arquiteto de uma rede, o promotor de suas relações sociais num universo construído por ele mesmo, podendo escolher entre uma multiplicidade de âmbitos e criar alternativas ao "individualismo e à solidão ameaçadora". Trata-se de condições que podem ser favoráveis a um novo pensamento de comunidade e sociabilidade fundado em relações de amizade e cooperação como contraposição a um confinamento que a vida moderna faz supor (Ortega, 2000) e que, na sala de aula, o ensino isolado de cada disciplina tende a reforçar. Entretanto, no espaço da aula de matemática, a indiferença perturbadora pode ceder lugar à restauração ou criação de vínculos entre professor e aluno, em que o conhecimento matemático seja objeto de interesse.

Dessas considerações coloca-se em destaque o princípio de que a interação, o diálogo, a cooperação e/ou colaboração, nas diferentes práticas sociais, entre elas, as práticas de sala de aula, evocam formas e valores associados ao desenvolvimento humano que sejam condição de existência para o exercício de ensinar e aprender matemática. Talvez sejam os elementos indispensáveis para uma espécie de pacto social amplo que, de modo particular, precisa ser instaurado na escola, essa escola hoje marcada por tensões (as de dentro e as de fora) que têm como sintoma e motor a desarticulação das equipes e, consequentemente, a 
falta de um projeto pedagógico por ela assumido, o desalento de professores, o desinteresse, indisciplina e agressividade de alunos etc.

Nessas condiçôes, aquilo que deveria fazer parte ou ser respondido por um projeto educacional da sociedade e/ou da escola termina por exigir decisões e respostas individuais do professor, perplexo que está, diante de uma situação para a qual não foi ou não está preparado. Assim, invertem-se papéis, pois o que é da esfera do coletivo é transferido para o plano individual. Não estando o projeto profissional do professor de matemática articulado ou em sintonia com o projeto coletivo da escola (se existe), e vice-versa, é muito provável que predomine o individualismo de parte a parte, inviabilizando a realização de uma necessidade coletiva: a escola e a matemática para todos.

\section{Outras considerações}

A importância e as aplicações de conhecimentos matemáticos, como vimos nos referindo, vão muito além do que conseguimos vislumbrar de imediato, o que reforça a idéia de que ao cidadão é necessário o domínio de algumas noçōes básicas de matemática.

Sendo a matemática uma construção humana em decorrência da relação do homem com a natureza e da vida em sociedade, o sentido para o que se aprende na escola é dado na medida em que os conhecimentos matemáticos adquiridos pelos sujeitos sejam utilizados para o entendimento de diferentes aspectos da cultura a que pertencem, para a comunicação e enfrentamento de situaçôes do cotidiano. Medir, contar, localizar e localizar-se, ler e interpretar informaçōes de gráficos, mapas e textos, argumentar ou contra-argumentar, resolver problemas e comunicar raciocínios feitos e resultados encontrados são alguns dos muitos usos da matemática. Processos e conceitos avançados são utilizados por matemáticos, cientistas e profissionais especializados em diferentes áreas, em situaçôes familiares ou não à grande maioria das pessoas, mas nem vistas, nem compreendidas por elas (Santos, 2002). Características como essas têm impacto sobre a formulação de currículos e sobre o ensino, dando margem a contraposiçôes de elementos que são mais dimensōes de um mesmo fenômeno do que dois pólos irreconciliáveis. Estão relacionadas a isso consideraçôes sobre se o conhecimento matemático é puro ou aplicado e se é construído ou descoberto 
por motivações endógenas ou exógenas, se ele tem um caráter formal ou referencial. E, em conseqüência, se no seu ensino a abordagem de conteúdos pauta-se pela lógica dos conhecimentos teóricos, pela lógica da sua construção histórica ou pela relevância social definida como diretriz de um projeto educacional.

Douady (1986) considerou que a construção de conhecimentos matemáticos pela criança apóia-se na dialética instrumento-objeto, segundo a qual, de maneira alternada, esses conhecimentos são tomados como instrumentos eficazes na resolução de problemas e como objetos identificados que podem ser estudados por si mesmos. Santaló et al. (1994) ressalta que na tarefa de dimensionarmos o nosso trabalho cabe a nós, professores, levarmos em conta tanto o valor formativo da matemática que ajuda a estruturar todo o pensamento e a agilizar o raciocínio dedutivo, quanto o caráter de ferramenta necessária à atuação diária e para muitas atividades específicas. Em que pese, para o autor, a variedade de matizes da matemática, que vai do seu aspecto mais puro às aplicações corriqueiras habituais, nos cabe, como professores, levar em conta e adaptar, em maior ou menor grau, os interesses particulares de cada aluno, pois a matemática tem uma dualidade importante e, por isso, pode interessar ao aluno.

Embora tendo partidas e objeto de interesses diferentes, essas idéias dialogam entre si e têm um denominador comum relativo à concepção de conhecimento matemático, de ensino e aprendizagem que, ao invés de opor, aproxima conteúdo e metodologia, conteúdo e contextos de aplicação desse conhecimento. Contêm subsídios que fundamentam o currículo de Matemática, a formação docente e o trabalho do professor ao abordar noções matemáticas específicas na sala de aula. Neste caso, postula-se uma articulação de dualidades.

\section{Recebido em dezembro de 2007 e aprovado em março de 2008.}

\section{Nota}

1. Lave e Wenger consideram uma comunidade de prática como um conjunto de relaçōes entre pessoas, atividades e mundo, sobretudo em uma relação tangencial e de envolvimento com outras comunidades de prática. Segundo Llinares (2000) uma comunidade de prática define um grupo social no qual seus membros compartilham uma determinada atividade (modos de fazer e comunicar-se). A comunidade de prática é uma condição intrínseca para a existência do conhecimento, no mínimo porque esta fornece o suporte de interpretação necessário para dar sentido a sua tradição. 


\section{Referências}

ABREU, G. A teoria das representações sociais e a cognição matemática. Quadrante: Revista Teórica e de Investigação, Lisboa, v. 4, n. 1, 1995. CASTORINA, J.A. et al. Piaget-Vygotsky: novas contribuições para o debate. São Paulo: Ática, 1995.

CHARLOT, B. A pesquisa educacional entre conhecimentos, políticas e práticas: especificidades e desafios de uma área de saber. Revista Brasileira de Educação, Rio de Janeiro, v. 11, n. 31, jan./abr. 2006.

D’AMBRÓSIO, U. Educação matemática: da teoria à prática. Campinas: Papirus, 1996.

DOUADY, R. Jeux de cadres et dialectique outil-objet. Recherches en Didactique des Mathematiques, Paris, v. 7, n. 2, 1986.

ERNST, P. Varieties of constructivism: their metaphors, epistemologies and pedagogical implications. Hiroshima Journal of Mathematics Education, Hiroshima, v. 2, p. 1-14, 1999.

LAVE, J.; WENGER, E. Situated learning: legitimate peripheral participations. Cambridge, Mass: Cambridge University, 1991.

LLINARES, S. Intentando compreender la práctica del profesor de matemáticas. In: Ponte, J.P.; Serrazina, L. (Org.). Educação matemática em Portugal, Espanha e Itália; actas da escola de verão-1999. Lisboa: SEM-SPCE, 2000.

MACHADO, N.J. Matemática e realidade. São Paulo: Cortez, 1987.

NISS, M. Las matemáticas en la sociedad. Uno: Revista de Didáctica de las Matemáticas, Barcelona, v. 2, n. 6, 1995.

ORTEGA, F. Amizade e estética da existência em Foucault. Rio de Janeiro: Graal, 1999.

SANTALÓ, L.A. et al. La enseñanza de las matemáticas en la educación intermedia. Madrid: RIALP, 1994.

SANTOS, V.M. A matemática no primeiro grau: o significado que pais, alunos e professores conferem à matemática. 1990. Dissertação (Mestrado) - Pontifícia Universidade Católica de São Paulo, São Paulo. 
A matemática escolar, o aluno e o professor...

SANTOS, V.M. Matemática: uma construção humana. In: Murrie, Z.F. Matemática: livro do estudante; ensino fundamental. Brasília, DF: MEC/INEP, 2002.

STEINER, H.-G. Teoria da educação matemática (TEM): uma introdução. Quadrante: Revista Teórica e de Investigação, Lisboa, v. 2, n. 2, 1993. 